\title{
Rare cause of repeated pulmonary embolism: a case of primary pleural squamous cell carcinoma and literature review
}

\author{
Zhongzhong Chen ${ }^{\dagger}$, Tingting Feng ${ }^{\dagger}$, Meng Wang, Xingxiang Xu, Yuxiu Wang, Yiran Li and Lingfeng Min ${ }^{*}$ (1)
}

\begin{abstract}
Background: Malignant tumors are risk factors for a pulmonary embolism (PE), and a PE caused by a tumor is not uncommon. Primary pleural squamous cell carcinoma (PPSCC) is a rare malignancy; thus, a related PE is extremely rare.

Case presentation: A previously healthy 49-year-old female patient was admitted to Northern Jiangsu People's Hospital owing to chest tightness, cough, and breathing difficulty that persisted for 3 days. Following admission, a computed tomography (CT) pulmonary angiography revealed an embolism in the main pulmonary artery, upper and lower pulmonary artery branch. The patient was treated with alteplase, warfarin, and antibiotics. Over the following year, she experienced recurrent chest pain and tightness and breathing difficulty, with multiple CT pulmonary angiography revealing thrombosis in the right and left main pulmonary artery. No abnormalities were observed in surrogate markers of autoimmune diseases, tumor antigen testing, or ultrasonography; thus, the cause of recurrent PE was not identified. Subsequently, a positron emission tomography-computed tomography (PET-CT) examination revealed diffuse heterogeneous thickening of the right pleura and substantially increased glucose metabolism. A CT-guided pleural biopsy was performed, and histopathological examination of the pleura eventually revealed a diagnosis of PPSCC.
\end{abstract}

Conclusions: PPSCC is a rare tumor that lacks specific clinical manifestations and is difficult to detect with imaging techniques. The occurrence of PE as the primary manifesting symptom in a patient with PPSCC is extremely rare. Thus, malignant tumors should be considered in patients with no risk factors for PE and/or in those with recurrent PE. An immediate diagnosis and adequate intervention can be achieved with increased awareness of this diagnosis and subsequent related examinations.

Keywords: Pulmonary embolism, Primary pleural squamous cell carcinoma, Pleural malignancy

\section{Background}

Primary tumors of the pleura are uncommon and primary pleural squamous cell carcinoma (PPSCC) is an exceedingly rare pleural malignancy which has seldom been reported [1, 2]. The clinical manifestations of PPSCC are not typical. In the early stages, patients with PPSCC are usually asymptomatic, with localized pleural

\footnotetext{
* Correspondence: minlingfeng@126.com

${ }^{\dagger}$ Zhongzhong Chen and Tingting Feng contributed equally to this work. Department of Respiratory and Critical Care Medicine, Northern Jiangsu People's Hospital, Dalian Medical University, Clinical Medical College of Yangzhou University, Yangzhou 225001, Jiangsu, China
}

thickening or small nodules noted on computed tomography $(\mathrm{CT})$ [3], which are difficult to detect, often leading to a misdiagnosis [2].

Venous thromboembolic events comprise deep vein thrombosis and pulmonary embolism (PE), which are common causes of morbidity and mortality, particularly in patients who are hospitalized or bedridden [4]. Malignancy is a known risk factor for venous thromboembolism; venous thromboembolism caused by malignant tumors is clinically not rare [5]. However, the onset of PPSCC characterized by a PE is extremely rare and has

(c) The Author(s). 2020 Open Access This article is distributed under the terms of the Creative Commons Attribution 4.0 International License (http://creativecommons.org/licenses/by/4.0/) which permits unrestricted use, distribution, and reproduction in any medium, provided you give appropriate credit to the original author(s) and the source, provide a link to the Creative Commons license, and indicate if changes were made. The Creative Commons Public Domain Dedication waiver (http://creativecommons.org/publicdomain/zero/1.0/) applies to the data made available in this article, unless otherwise stated. 
not been reported in the literature to date. In the present study, we described a case of PPSCC with PE as the first manifestation. Because of this unusual presentation, it was difficult to clinically detect the tumor, resulting in delayed accurate diagnosis and appropriate treatment.

\section{Case presentation}

In June 2017, a 49-year-old Chinese woman was admitted to the emergency department of the Northern Jiangsu People's Hospital owing to chest tightness and breathing difficulty that persisted for 3 days. She was previously in good health and was a non-smoker. In addition, she had fever, chills, and a maximum body temperature of $38^{\circ} \mathrm{C}$. She did not have urinary or fecal incontinence, chest pain, general fatigue, cough, or hemoptysis during the course of her disease. Following admission, results of complete blood test revealed that white blood cell count was $12.21 \times 10^{9}$ cells/L and the percentage of large white blood cells was $85.5 \%$. Blood gas analysis results showed 7.480 $\mathrm{PH}, 100 \mathrm{mmHg} \mathrm{PaO}_{2}$, $31 \mathrm{mmHg} \mathrm{PaCO}_{2}$, and $23.1 \mathrm{mmol} / \mathrm{L} \mathrm{HCO}^{3-}$. D-dimer assay indicated a value of $5.28 \mathrm{mg} / \mathrm{L}$. A computed tomography pulmonary angiography (CTPA) revealed filling defects in the main pulmonary artery, upper and lower pulmonary artery branch (Fig. 1). There were no distinct signs of embolism in color ultrasonography examination of the upper and lower limbs. The patient was diagnosed with PE, and was treated with anticoagulation, antiplatelet aggregation, and anti-infection medications. During the $18 \mathrm{~h}$ after admission, the patient experienced worsening shortness of breath and anoxia and was subsequently transferred to the Emergency Intensive Care Unit (EICU) for non-invasive ventilator assisted ventilation. Additionally, the patient was intravenously administered alteplase once every $12 \mathrm{~h}$ for 3 consecutive days and 5000 units subcutaneous unfractionated heparin. Warfarin $(5 \mathrm{mg})$ was orally administered once a day. On noting that the prothrombin time (PT) and international normalized ratio (INR) were 2-2.5 times their respective normal levels, warfarin therapy was singly administered along with anti-infective, supportive, and oxygen therapies. Once her condition had considerably improved and the anoxia was reduced, she was discharged from the hospital.

After 10 days, dyspnea and chest tightness recurred. In addition, she experienced persistent right chest pain, which aggravated when she lied on her right side and was not relieved by rest. Minor vaginal bleeding was also observed. She presented to the Department of Respiratory and Critical Care Medicine of our hospital for a CTPA, which revealed filling defects in the left and right branches of pulmonary artery as well as bilateral pleural effusion (Fig. 2). A routine coagulation test revealed $37 \mathrm{~s}$ PT and 3.33 INR, and a D-dimer assay showed a value of $8.75 \mathrm{mg} / \mathrm{L}$. No abnormalities were observed in limb color ultrasonography, tumor antigen testing, or surrogate markers of autoimmune diseases (anti-nuclear antibody, anti-RNP antibody, anti-CCP antibody, c-ANCA, p-ANCA, anti-SS-A antibody, and anti-SS-B antibody). Based on the monitoring of PT and INR, we decided to discontinue warfarin to prevent an overdose situation. Relevant contraindications were excluded and the patient underwent interventional inferior vena cava filter implantation combined with thrombolysis implantation therapy, along with low-dose urokinase. Following surgery, she continued to receive anticoagulant treatment. On considerably improvement in her condition, she was discharged.

One month later, she was referred to our hospital again due to swelling in her right lower limb. She received interventional inferior right iliac vein dilation and stent placement. In October 2018, she presented again with a week-long history of right-sided chest pain, cough, difficulty in breathing, and weight loss. A CTPA

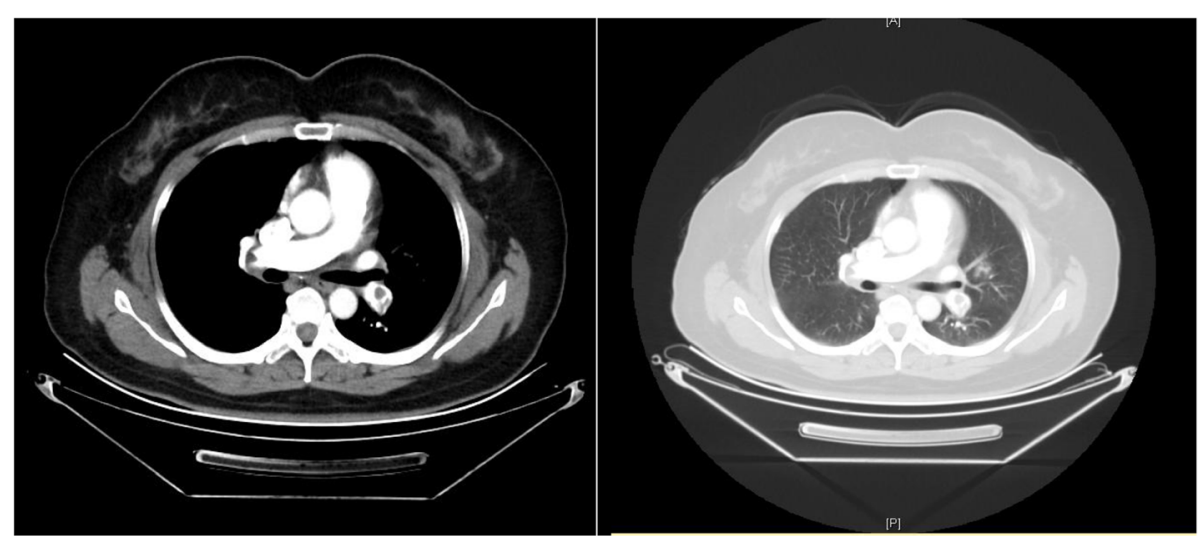

Fig. 1 Computed tomography pulmonary angiography (CTPA) revealing filling defects in the main pulmonary artery and upper and lower pulmonary artery branch 


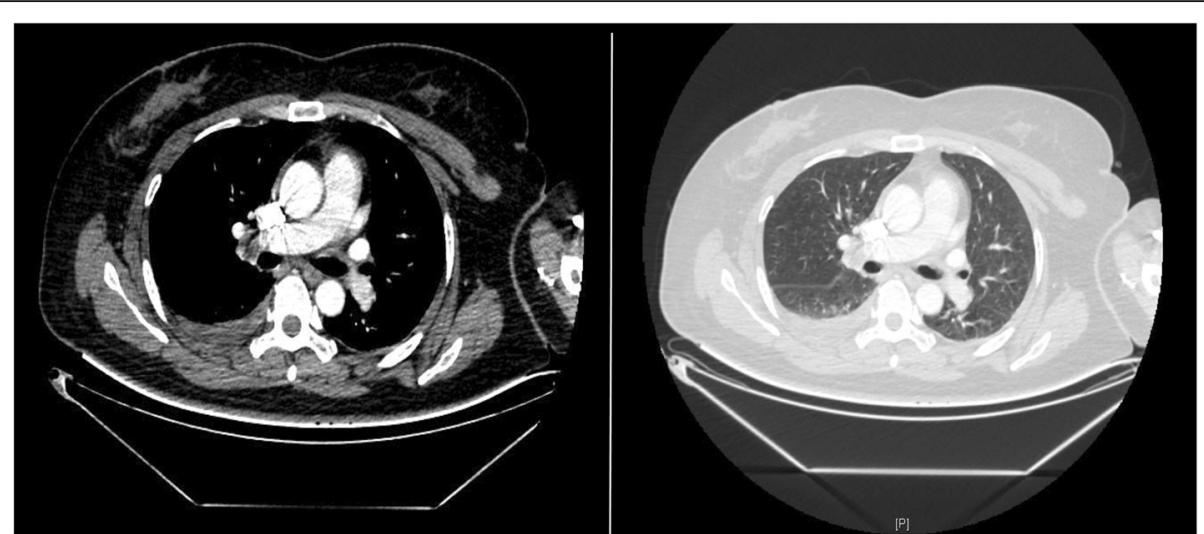

Fig. 2 Computed tomography pulmonary angiography (CTPA) revealing filling defects in the left and right branches of pulmonary artery as well as bilateral pleural effusion

(Fig. 3) revealed no evident improvement of the thrombosis in the right and left main pulmonary artery, progression of pneumonia, and a reduced right pleural effusion, compared with the previous CTPA. Once again, the tumor associated antigen test was performed. Tumor antigen testing revealed an elevated Ca125 level of 69.16 $\mathrm{U} / \mathrm{ml}$ (normal value $<35 \mathrm{U} / \mathrm{ml}$ ) and Ca199 level of 30.22 $\mathrm{U} / \mathrm{ml}$ (normal value $<27 \mathrm{U} / \mathrm{ml}$ ). She was treated with anticoagulation, anti-infection, supportive, and oxygen therapies. We recommended her to undergo a positron emission tomography-computed tomography (PET-CT) test, but she refused and was discharged from the hospital.

She subsequently underwent a PET-CT examination in another hospital. The PET-CT revealed diffuse heterogeneous thickening of the right pleura, substantially increased glucose metabolism, fluorodeoxyglucose (FDG) uptake on L5 vertebral body, striated soft tissue lesions along the right iliac vein, and increased FDG uptake. In November 2018, she was once again admitted to our hospital. Results of enhanced chest CT scan revealed a bilateral PE, bilateral pulmonary infection, right pleural thickening, and pleural effusion (Fig. 4). She completed the CT-guided pleural biopsy and postoperative histopathology revealed the tumor consisting of squamous cells were arranged in the nest bulk with invasive growth (Fig. 5a). Immunohistochemical (IHC) staining was performed for pleural lesion was positive for P63 (Fig. 5b), P40 (Fig. 5c), CK5/6 (Fig. 5d), epithelial membrane antigen (EMA) and negative for CD5 (Fig. 5e), CD117 and Calretinin (Fig. 5f). Combining with the IHC analysis, the pathological diagnosis was squamous cell carcinoma. Based on her medical history and results of histopathological examination and imaging, the patient was finally diagnosed with PPSCC.

Between 1977 and 2019, we identified 9 previous reports of squamous cell carcinoma arising from the pleura in patients. As described in Table 1, patients ranged in age between 49 and 75 . These cases underwent chest pain, cough, dyspnoea, and other clinical

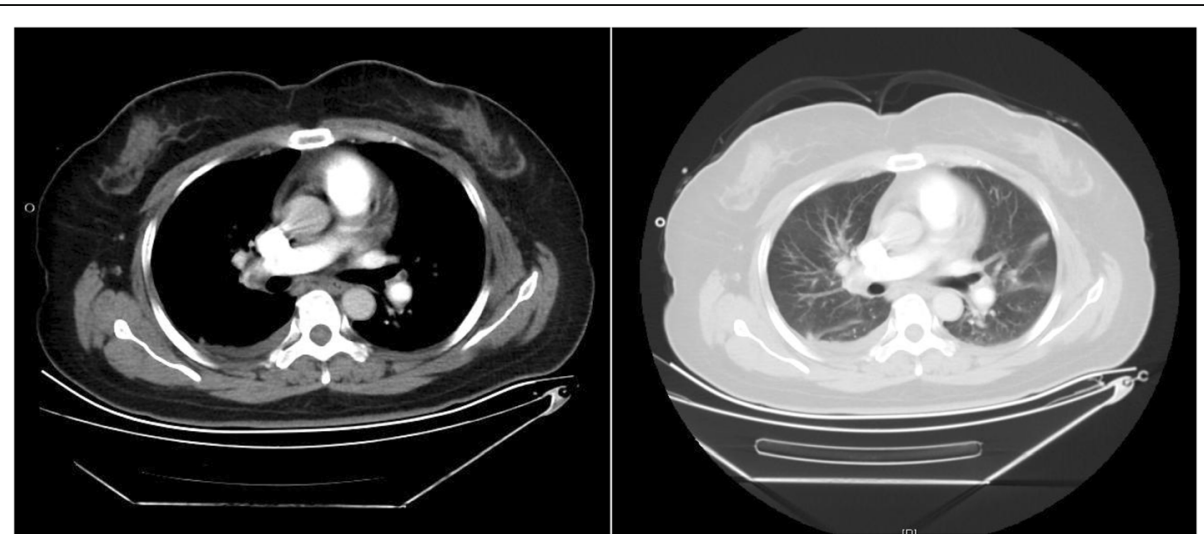

Fig. 3 Computed tomography pulmonary angiography (CTPA) revealing no evident improvement of the thrombosis in the right and left main pulmonary artery, but a disappearance of the right pleural effusion 


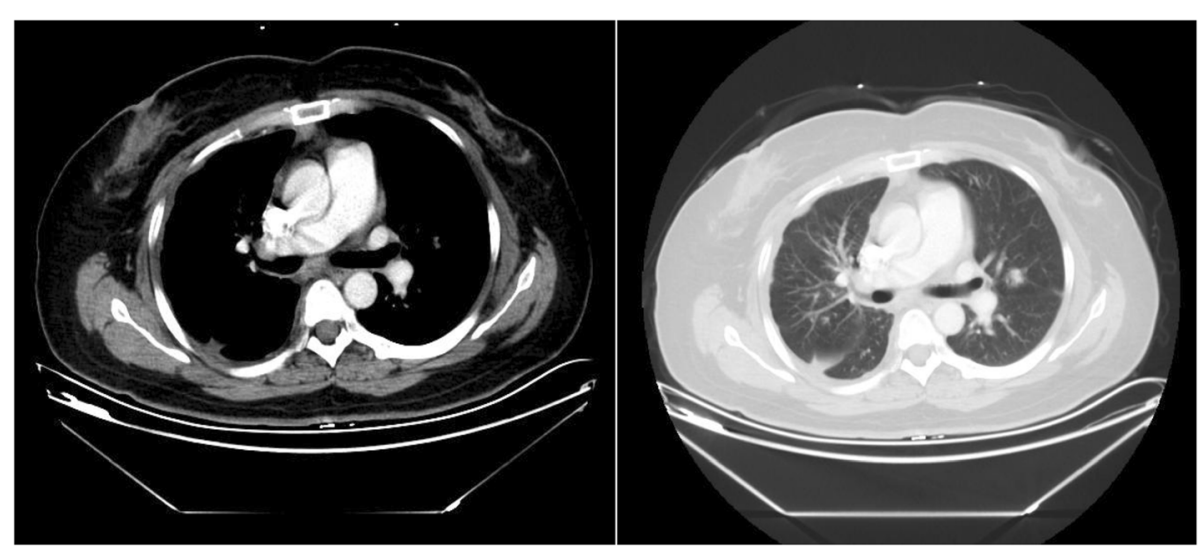

Fig. 4 Enhanced chest computed tomography (CT) scan revealing bilateral pulmonary embolism, bilateral pulmonary infection, right pleural thickening and pleural effusion
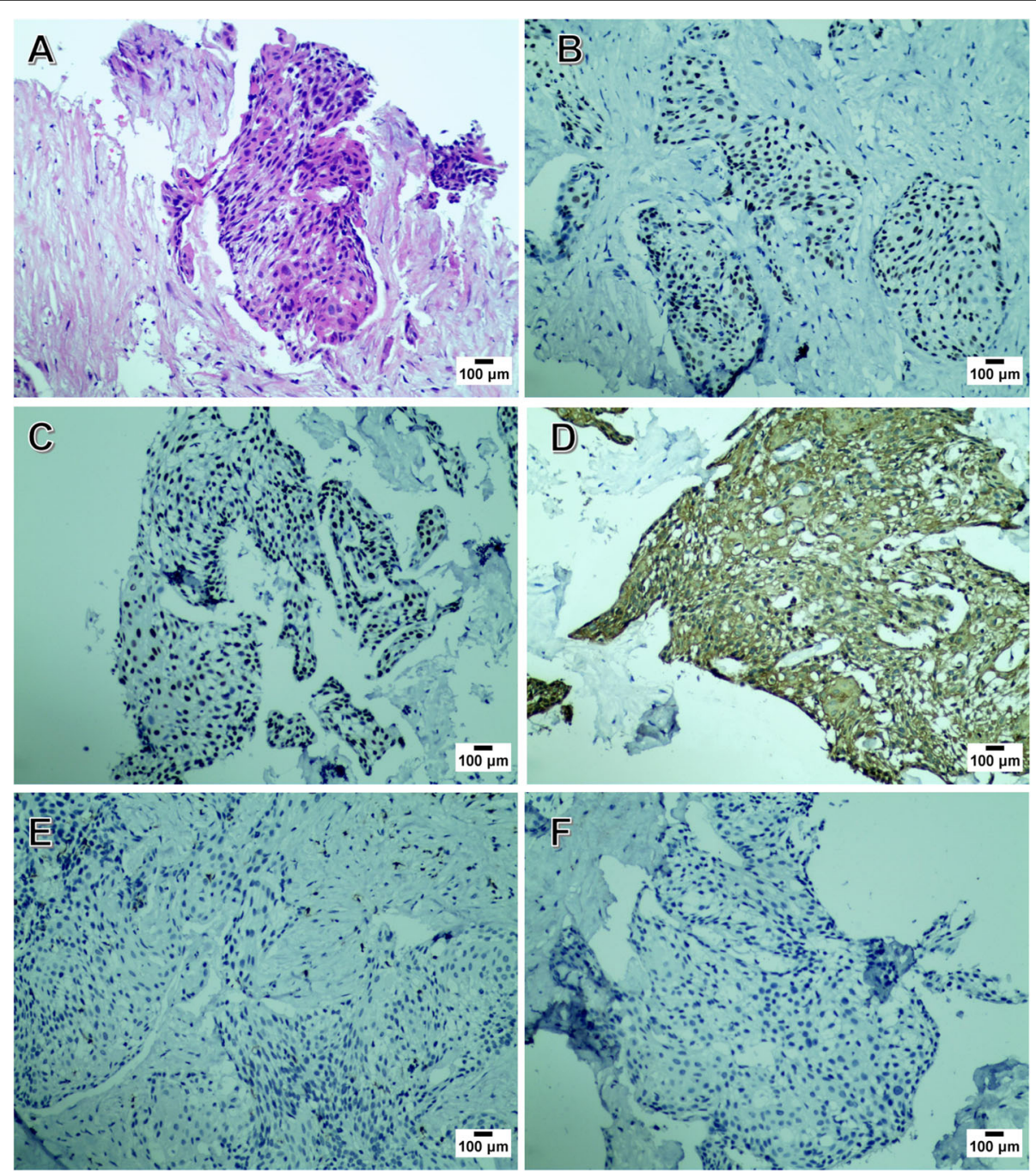

Fig. 5 a Tumor consisted of squamous cells arranged in the nest bulk with invasive growth (hematoxylin and eosin staining, $\times 200$ ). $\mathbf{b} \| H C$ staining of P63 was positive, $\times 200$. c $1 H C$ staining of P40 was positive, $\times 200$. d $1 H C$ staining of $C K 5 / 6$ was positive, $\times 200$. e $1 H C$ staining of CD5 was negative, $\times 200$. $\mathbf{f} \| \mathrm{HC}$ staining of Calretinin was negative, $\times 200$ 
Table 1 Clinical features of cases that describe primary pleural squamous cell carcinoma

\begin{tabular}{|c|c|c|c|c|c|c|}
\hline Case & Age / Sex & Tumor location & Past medical history & Clinical symptoms & Treatment & Follow-up and outcome \\
\hline Rüttner 1977 [6]- Case 1 & $49 / M$ & Right & Empyema & NA & $S$ & 36 months, Live \\
\hline Rüttner 1977 [6]- Case 2 & $43 / F$ & Left & Pneumothorax & Cough, Hemoptysis & S & NA \\
\hline Garty 1987 [1] & $61 / M$ & Right & Empyema & Cough, Chest pain & S & NA \\
\hline Prabhakar 1989 [7] & $58 / F$ & Left & BPF, Empyema & Cough, Hemoptysis & S & 5 months, Die \\
\hline Sapino 1996 [3] & $65 / M$ & Right & Pneumothorax & Dyspnea, Chest pain & PT & 1 months, Die \\
\hline Zapatero 2004 [8] & $45 / M$ & Right & BPF, Empyema & Fever, Dyspnea & S & 6 months, Die \\
\hline Mark 2010 [9] & $67 / M$ & Right & BPF & Chest pain & PT & 4 months, Die \\
\hline Lin 2013 [2] & $75 / F$ & Right & NA & Cough, Chest pain & $S+R$ & 38 months, Live \\
\hline Ronchi 2018 [10] & $56 / M$ & Right & NA & Cough, Dyspnoea & C & NA \\
\hline Jeon 2017 [11]- Case 1 & $74 / M$ & Left & BPF, Empyema & Chest pain & $\mathrm{R}$ & NA \\
\hline Jeon 2017 [11]- Case 2 & $53 / F$ & Right & Empyema & Chest pain & $\mathrm{R}$ & 5 months, Die \\
\hline Present case & $49 / F$ & Right & NA & Chest pain & PT & NA \\
\hline
\end{tabular}

$M$ male, $F$ female, BPF bronchopleural fistula, $S$ surgery, $C$ chemotherapy, $R$ radiotherapy, $P T$ palliative treatment, NA not available

symptoms. Most lesions of these patients were observed in the right pleura. Most of the cases had been in long standing chronic empyema, bronchopleural fistula or pneumothorax before a diagnosis of squamous cell carcinoma. But in our case, the patient was previously healthy without chronic empyema or bronchopleural fistula. After being diagnosed with pulmonary embolism, our patient experienced recurrent chest wall pain and pulmonary embolism.

\section{Discussion and conclusions}

$\mathrm{PE}$ is a clinical syndrome in which an artery in the lungs is blocked by a substance such as a gas or thromboembolism, with a thromboembolism being the most common cause. Cancer is a well-known risk factor for $\mathrm{PE}$, and lung cancer is the most common malignancy coexisting in patients with PE [12]. Studies have demonstrated that the risk of thromboembolic events in patients with cancer is much greater than that in the general population [13], with some studies reporting that patients with cancer are at a 4-7-fold higher risk of PE than those without cancer [5, 14]. Blom et al. reported that patients with hematologic malignancies are at the highest risk of PE, followed by those with lung and gastrointestinal cancers [5]. In addition, venous thrombosis is probably a symptom of occult malignancy, with $\mathrm{PE}$ often being the first symptom in patients with malignant tumor [15]. Similarly, this patient with PPSCC presented in a subtle manner, with $\mathrm{PE}$ as the initial symptom. Owing to the rarity of PPSCC, no published reports exist that describe PPSCC presenting with PE.

The most common pleural malignancies are metastases from primary tumors such as lung or breast cancers [16]. Primary tumors of the pleura are uncommon, accounting for $10 \%$ of all pleural neoplasms [17]. Because PPSCC is particularly rare, the pathogenesis and incidence of this tumor is unclear [10]. To date, no association has been demonstrated between PPSCC and environmental factors classically associated with other pleural and pulmonary neoplasms, such as tobacco and asbestos exposure [7]. However, we conducted a literature search and found some cases of squamous cell carcinoma arising from the pleura in patients with chronic empyema or subjected to therapeutic pneumothorax for active tuberculosis $[3,18]$. Thus, we can not exclude that chronic inflammation may be one of the causes of PPSCC.

Early PPSCC is usually asymptomatic and morphologically similar to pleural mesothelioma, which is easily misdiagnosed as localized pleural mesothelioma [2]. However, as the disease progresses, patients may experience chest pain, cough, expectoration, fatigue, weight loss, and other atypical symptoms $[1,8]$. In our case, the patient was previously healthy without any chronic pleural inflammation. After being diagnosed with PE, our patient experienced right chest pain, dyspnea and hemoptysis. The patient's pain continued to worsen and was accompanied with pleural effusion. We considered that the local pleural tumor gradually invaded the chest wall, ribs, and intercostal nerves, resulting in bone destruction and continuous pain caused by nerve stretch.

The morphology of PPSCC lacks specificity, and only local pleural thickening can be observed on chest radiography or $\mathrm{CT}$, which cannot distinguish between benign and malignant tumors. Pleural fluid cytology for malignant cells is the simplest way to diagnose malignant tumors, but the diagnostic yield of pleural fluid cytology is low [19]. In recent years, PET-CT has been increasingly used to diagnose and stage primary malignancies [20]. Some reports have confirmed that a PET-CT can accurately distinguish between benign and malignant tumors, as pleural malignancy shows increased FDG uptake [20, 
21]. The gold standard for the diagnosis of a pleural tumor involves the pathological analysis of a pleural biopsy. Percutaneous CT-guided Tru-Cut needle biopsies are considered a superior diagnostic method. The reported rate of diagnostic sensitivity on CT guidance to target areas of pleural disease has been shown to increase the sensitivity to $87.5 \%$ [22]. However, thoracoscopy pleural biopsy is now widely considered the gold standard diagnostic modality with a diagnostic yield of up to $99 \%[23,24]$.

Early detection, early resection, and thorough removal of tumors are important for the treatment of primary pleura tumors and prevention of recurrence. Total surgical resection is the best treatment for early PPSCC. As a minimally invasive procedure, video-assisted thoracoscopic surgery (VATS) is the optimal method for the removal of early pleural tumors $[25,26]$. Early PPSCC can be removed by VATS; if it is not possible to obtain the surgical margin of the tumor using VATS, the procedure should be converted to an open thoracotomy [27]. For tumors with unclear boundaries and suspected malignant pleural nodules, intraoperative frozen examination should be used to determine whether an extended resection should be performed to reduce the risk of recurrence and improve the prognosis [2, 25]. Radiotherapy and chemotherapy are considered for patients with recurrence or for those who are inoperable. However, little data exists regarding the efficacy of radiotherapy and chemotherapy in these patient groups. Owing to the recurrence of $\mathrm{PE}$ in our patient, her condition was severe and she was administered palliative treatment.

In conclusion, PPSCC is a rare pleural tumor, with a lack of specificity in its clinical manifestations and related findings on imaging. Early PPSCC is difficult to detect, which may result in substantial delays in the diagnosis and treatment. However, PET-CT is a crucial functional imaging technique for detecting malignant pleural lesions and assessing the extent of tumor involvement. Malignant tumors should be considered in patients with no risk factors for PE and in those with recurrent or refractory PE. PE is likely to be a symptom of occult malignancy. In this situation, a careful physical examination together with imaging-assisted techniques and measurement of tumor markers is of utmost importance to promptly identify a tumor.

\section{Abbreviations}

CT: Computed tomography; CTPA: Computed tomography pulmonary angiography; EMA: Epithelial membrane antigen; FDG: Fluorodeoxyglucose; IHC: Immunohistochemical; INR: International normalized ratio; PE: Pulmonary embolism; PET-CT: Positron emission tomography-computed tomography; PPSCC: Primary pleural squamous cell carcinoma; PT: Prothrombin time; VATS: Video-assisted Thoracoscopic Surgery

\section{Authors' contributions}

ZC and TF completed the literature search. MW, YW and YL collected patient information. ZC and TF designed and wrote the manuscript. LM is the physician who was involved in the case, and is the main preceptor. LM and XX revised the manuscript. All authors read and approved the final manuscript.

\section{Funding}

This work was supported by the National Natural Science Foundation of China [Grant numbers 81870033, 81302016, 81302015], the Six Talent Peaks Poject of Jiangsu Province [Grant number WSN-106], the Medical Scientific Research Foundation of Jiangsu Province of China [Grant numbers QNRC2016340], the Foundation for High-level Talents during the 13th Fiveyear Plan Period of Yangzhou, China [Grant numbers ZDRC201866].

This funding body also had no influence on the design of the study and collection, analysis, and interpretation of data and in writing the manuscript.

\section{Availability of data and materials}

The datasets used and/or analyzed during the current study are available from the corresponding author on reasonable request.

\section{Ethics approval and consent to participate}

The study was performed in accordance with the Declaration of Helsinki and was approved by Medical Ethics Committee of North jiangsu People's Hospital.

\section{Consent for publication}

The patient gave consent for publication and consent for publication was written. A copy of the written consent is available for review by the Editorin-Chief of this journal.

\section{Competing interests}

The authors declare that they have no competing interests.

Received: 21 June 2019 Accepted: 5 February 2020

Published online: 26 March 2020

\section{References}

1. Garty I, Straussberg R, Flatau E. Extraosseous 99mTc-MDP uptake in squamous cell carcinoma of the pleura. Eur J Nucl Med. 1987;12(12):589-91.

2. Lin XM, Chi C, Chen J, Liu Y, Li P, Yang Y. Primary pleural squamous cell carcinoma misdiagnosed as localized mesothelioma: a case report and review of the literature. J Cardiothorac Surg. 2013;8:50.

3. Sapino A, Cavallo A, Donna A, Bussolati G. Pleural epidermoid carcinoma from displaced skin following extrapleural pneumothorax in a patient exposed to asbestos. Virchows Arch. 1996:429(2-3):173-6.

4. Streiff MB. Diagnosis and initial treatment of venous thromboembolism in patients with cancer. J Clin Oncol. 2009:27(29):4889-94.

5. Blom JW, Doggen CJ, Osanto S, Rosendaal FR. Malignancies, prothrombotic mutations, and the risk of venous thrombosis. JAMA. 2005;293(6):715-22.

6. Ruttner JR, Heinzl S. Squamous-cell carcinoma of the pleura. Thorax. 1977; 32(4):497-500.

7. Prabhakar G, Mitchell IM, Guha T, Norton R. Squamous cell carcinoma of the pleura following bronchopleural fistula. Thorax. 1989;44(12):1053-4.

8. Zapatero GJ, Garcia FC, Jimenez HL, Penalver PR, Fogue COL, Muguruza TI, Lago VJ. Carcinoma arising in the pleural cavity following pneumonectomy for hydatid disease. Respiration. 2004;71(3):285-8.

9. Franke M, Chung HD, Johnson FE. Squamous cell carcinoma arising from the pleura after pneumonectomy for squamous cell carcinoma of the lung. Am J Surg. 2010;199(4):e34-5.

10. Ronchi A, Cozzolino I, Montella M, Vicidomini G, Morgillo F, Della CC, Franco $\mathrm{R}$, Accardo M. Primary pleural squamous cell carcinoma: A diagnostic challenge. Cytopathology. 2018;29(2):205-7.

11. Jeon YJ, Shin S, Shim YM. Squamous cell carcinoma arising from the pleural cavity after pneumonectomy for chronic empyema. Korean J Thorac Cardiovasc Surg. 2017;50(2):123-5.

12. van Es N, Louzada M, Carrier M, Tagalakis V, Gross PL, Shivakumar S, Rodger MA, Wells PS. Predicting the risk of recurrent venous thromboembolism in patients with cancer: a prospective cohort study. Thromb Res. 2018;163:41-6.

13. Ma $L$, Wen Z. Risk factors and prognosis of pulmonary embolism in patients with lung cancer. Medicine (Baltimore). 2017;96(16):e6638. 
14. Lyman GH, Khorana AA, Falanga A, Clarke-Pearson D, Flowers C, Jahanzeb M, Kakkar A, Kuderer NM, Levine MN, Liebman H, et al. American Society of Clinical Oncology guideline: recommendations for venous thromboembolism prophylaxis and treatment in patients with cancer. J Clin Oncol. 2007;25(34):5490-505.

15. den Exter PL, Hooijer J, Dekkers OM, Huisman MV. Risk of recurrent venous thromboembolism and mortality in patients with cancer incidentally diagnosed with pulmonary embolism: a comparison with symptomatic patients. J Clin Oncol. 2011;29(17):2405-9.

16. Gkogkou C, Samitas K, Foteinou M. Primary pleural epithelioid mesothelioma of clear cell type: a case report and review of current literature. Ultrastruct Pathol. 2011;35(6):267-70.

17. Galateau-Salle F, Churg A, Roggli V, Travis WD. The 2015 World Health Organization classification of tumors of the pleura: advances since the 2004 classification. J Thorac Oncol. 2016:11(2):142-54.

18. Willen R, Bruce T, Dahlstrom G, Dubiel WT. Squamous epithelial cancer in metaplastic pleura following extrapleural pneumothorax for pulmonary tuberculosis. Virchows Arch A Pathol Anat Histol. 1976;370(3):225-31.

19. Bhattacharya S, Bairagya TD, Das A, Mandal A, Das SK. Closed pleural biopsy is still useful in the evaluation of malignant pleural effusion. J Lab Physicians. 2012;4(1):35-8.

20. Yamamoto $Y$, Kameyama R, Togami T, Kimura N, Ishikawa S, Yamamoto $Y$, Nishiyama Y. Dual time point FDG PET for evaluation of malignant pleural mesothelioma. Nucl Med Commun. 2009:30(1):25-9.

21. Johnson GB, Peller PJ, Kemp BJ, Ryu JH. Future of thoracic PET scanning Chest. 2015;147(1):25-30

22. Metintas M, Ak G, Dundar E, Yildirim H, Ozkan R, Kurt E, Erginel S, Alatas F, Metintas S. Medical thoracoscopy vs $C T$ scan-guided Abrams pleural needle biopsy for diagnosis of patients with pleural effusions: a randomized, controlled trial. Chest. 2010;137(6):1362-8

23. Harris RJ, Kavuru MS, Mehta AC, Medendorp SV, Wiedemann HP, Kirby TJ, Rice TW. The impact of thoracoscopy on the management of pleural disease. Chest. 1995:107(3):845-52.

24. Menzies R, Charbonneau M. Thoracoscopy for the diagnosis of pleural disease. Ann Intern Med. 1991;114(4):271-6.

25. Magdeleinat P, Alifano M, Petino A, Le Rochais JP, Dulmet E, Galateau F, Icard P, Regnard JF. Solitary fibrous tumors of the pleura: clinical characteristics, surgical treatment and outcome. Eur J Cardiothorac Surg. 2002;21(6):1087-93.

26. Cardillo G, Facciolo F, Cavazzana AO, Capece G, Gasparri R, Martelli M. Localized (solitary) fibrous tumors of the pleura: an analysis of 55 patients. Ann Thorac Surg. 2000;70(6):1808-12.

27. Ang KL, Tan C, Hsin M, Goldstraw P. Intrapleural tumor dissemination after video-assisted thoracoscopic surgery metastasectomy. Ann Thorac Surg. 2003;75(5):1643-5

\section{Publisher's Note}

Springer Nature remains neutral with regard to jurisdictional claims in published maps and institutional affiliations.

Ready to submit your research? Choose BMC and benefit from:

- fast, convenient online submission

- thorough peer review by experienced researchers in your field

- rapid publication on acceptance

- support for research data, including large and complex data types

- gold Open Access which fosters wider collaboration and increased citations

- maximum visibility for your research: over $100 \mathrm{M}$ website views per year

At $\mathrm{BMC}$, research is always in progress.

Learn more biomedcentral.com/submissions 